\title{
Utilisation of FIB/SEM Technology in the Assembly of an Innovative Micro-CMM Probe
}

\author{
Daniel Smale ${ }^{1}$, Steve Haley ${ }^{1}$, Joel Segal ${ }^{1}$, Ronaldo Ronaldo ${ }^{1}$, Svetan Ratchev ${ }^{1}$, \\ Richard K. Leach ${ }^{2}$, and James D. Claverley ${ }^{2}$ \\ ${ }^{1}$ Precision Manufacturing Centre, University of Nottingham, UK \\ ${ }^{2}$ Industry \& Innovation Division, National Physical Laboratory, Teddington, UK
}

\begin{abstract}
The measurement of features from the micro- and precision manufacturing industries requires low uncertainties and nano-scale resolution. These are best delivered through ultra precise co-ordinate measuring machines (CMMs). However, current CMMs are often restricted by the relatively large and insensitive probes used. This paper focuses on the assembly challenges of a novel micro-CMM probe. The probe is comprised of a $70 \mu \mathrm{m}$ glass sphere, attached to a solid tungsten-carbide shaft of diameter less than $100 \mu \mathrm{m}$, joined to a piezoelectric flexure structure. The assembly requirements are for positional accuracy of $\pm 0.5 \mu \mathrm{m}$, angle between the shaft and flexure of $90^{\circ} \pm 0.29^{\circ}$ and that the components be undamaged by the process. A combined Focused Ion Beam and Scanning Electron Microscope machine (FIB/SEM) with integrated nanoresolution manipulators was used. The investigation has evaluated potential assembly and joining solutions, identified modifications to existing equipment and product design and produced a set of prototypes.
\end{abstract}

Keywords: Ultra Precision Assembly, Microscopy, FIB Machining.

\section{Introduction}

Miniaturisation and integration of mechanical, sensing, and control functions within confined spaces is becoming an important trend in designing new products for commercial sectors such as medical, automotive, biomedical, consumer electronics, and telecommunications [1]. However, the potential for micro-assembly for such products has been shown mainly in the research environment with a limited transfer of knowledge and equipment to industry [2]. These key commercial sectors require that the related products are manufactured to a very high quality and reliability; therefore, metrology is of great importance [3].

The measurement and quantification of features and products from the microscale and precision manufacturing industries often requires uncertainties and resolution in the nanometre range. The best means of delivering these requirements is through high accuracy CMMs [4]. However, the current state-of-the-art CMMs are often restricted by the relatively large and insensitive probes used. An example of such a machine is the Zeiss F25, shown in Figure 1. The F25 has a quoted volumetric accuracy of 250 nm. Work at the Precision Manufacturing Centre (PMC) and the National Physical 


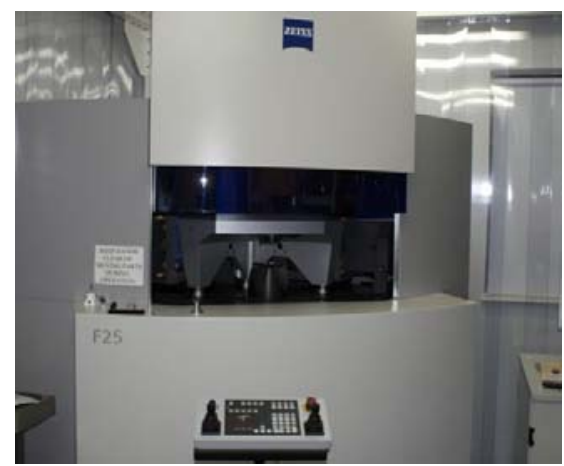

Fig. 1. Image of the Zeiss F25 CMM, located in Fig. 2. Image of the micro CMM probe, dethe PMC facilities

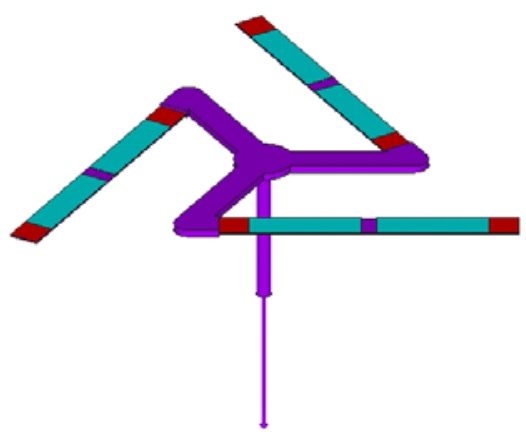

signed by NPL

Laboratory (NPL) has suggested that the F25 is more accurate than claimed by Zeiss and that the existing probes do not enable full exploitation of the machine's resolution.

The micro-CMM probe discussed in this paper was developed at NPL to help realise the accuracy and traceability required by the microscale and precision manufacturing industries [5]. The probe is comprised of a solid shaft, a flexure assembly, and a probing sphere. A 3D model of the device is shown in Figure 2. The shaft is manufactured from tungsten carbide (WC) via EDM and wire eroding. The flexure assembly is a laminar structure, manufactured by a micromachining process. The flexures include PZT actuators and sensors that are deposited onto the surface of the structure during the manufacturing process. The probing sphere attached to the end of the WC shaft is made of silica. The shaft is $100 \mu \mathrm{m}$ in diameter where it joins the flexure and $50 \mu \mathrm{m}$ in diameter where it joins the probing sphere. The shaft is connected at the thick end to the delicate piezoelectric flexure structure via a $50 \mu \mathrm{m}$ diameter spigot. At the thin end a $70 \mu \mathrm{m}$ diameter glass sphere is connected concentrically. These joints must be made without damaging any of the components, but special attention is placed on the protection of the sphere. The assembly requirements for the shaft onto the flexure specify a positional accuracy of $\pm 0.5 \mu \mathrm{m}$ and the angle between the shaft and flexure to be $90^{\circ} \pm 0.29^{\circ}$. These factors are of primary importance in ensuring correct function of the final product. Assembly is achieved through the application of micro-manipulators integrated within a combined FIB/SEM. The joint is made permanent through two options: adhesive bonding and FIB material deposition.

\section{Methodology}

\subsection{Assembly Challenges}

The micro-CMM probe described presents a number of specific assembly challenges. These challenges result from the scale of the parts and the technical requirements of the product. A study by Van Brussel [6] found that as the radius of a part falls below $1 \mathrm{~mm}$, 
the predominant forces acting upon it change, as shown in Figure 3. In particular, the effects of gravity (Fgrav) become negligible for radii of less than $0.1 \mathrm{~mm}$, with surface tension (Ftens) and van der Waals (Fvdw) forces becoming dominant. In order to fully evaluate the challenges and potential solutions, it was first necessary to identify the individual assembly operations. To this end, the assembly operations proposed by Rampersad [7] were used to define the operations specific to this application. This was further enhanced by the use of the Design for Micro Assembly methodologies proposed by Ratchev and Koelemeijer [2]. As a result of this analysis, an assembly operation hierarchy was produced. This hierarchy is headed by the required outcome of the process, in this case, 'Micro-CMM probe assembly'. This outcome is broken down into two assembly tasks; each of these tasks is sub-divided into several assembly operations. Each of the assembly operations was analysed, with respect to the two core factors, as a means of determining the challenges faced and thus identifying a preliminary route for generating a solution. The results of this are shown in Table 1.

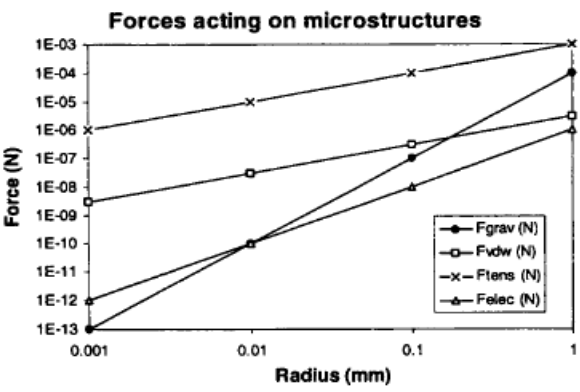

Fig. 3. The forces acting on an object with a radius of less than $1 \mathrm{~mm}$

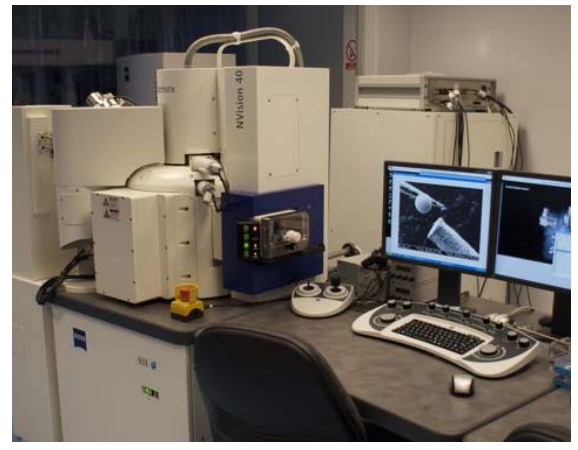

Fig. 4. The Zeiss NVision 40 FIB/SEM Crossbeam

\subsection{Solution Development}

With the challenges and requirements identified above and in previous trials [8], the next step in the work involved is identifying potential solutions to each operation. The first assembly task, hereafter referred to as Assembly Task 1, was to join the flexure and the shaft. The second assembly task, Assembly Task 2, is joining the sphere and the shaft. Both proposed solutions make use of the Zeiss NVision 40 FIB/SEM Crossbeam with integrated Kleindiek micro manipulators (Zeiss NVision), shown in Figure 4.

NPL provided the parts for all initial trials, namely: the piezoelectric flexure, the shaft and the probing sphere. However, the manufacturing process used by NPL could not guarantee the dimensions or even the presence of the hole in the flexure in which the shaft would be mounted. Therefore the preparations for Assembly Task 1, the joining of the shaft and flexure, were to test whether the Zeiss NVision could be used to machine the hole in the flexure. 
Table 1. Summary of the key challenges and requirements for each of the assembly operations within the assembly tasks

\begin{tabular}{|c|c|c|}
\hline $\begin{array}{l}\text { Assembly } \\
\text { Operation }\end{array}$ & Challenges & Requirements \\
\hline $\begin{array}{l}\text { 1.1 Handle/Fix } \\
\text { Flexure }\end{array}$ & $\begin{array}{l}\text { - Very thin }(15 \mu \mathrm{m}) \text { flexures } \\
\text { - Delicate structure }\end{array}$ & $\begin{array}{l}\text { - Keep electrical contacts clear } \\
\text { - Minimise stress on flexure }\end{array}$ \\
\hline $\begin{array}{l}1.2 \text { Drill hole in } \\
\text { Flexure }\end{array}$ & $\begin{array}{l}\text { - Thin and delicate flexures } \\
\text { - Comparatively large } \\
\text { dimensions for FIB machining }\end{array}$ & $\begin{array}{l}\text { - Do not damage flexure } \\
\text { - Small tolerance for hole diameter }\end{array}$ \\
\hline $\begin{array}{l}\text { 1.3 Handle/Fix } \\
\text { Shaft }\end{array}$ & $\begin{array}{l}\text { - Gravity no longer dominant } \\
\text { force acting on part } \\
\text { - WC is stiff but brittle }\end{array}$ & $\begin{array}{l}\text { - Minimise acceleration and } \\
\text { external forces } \\
\text { - Preserve the delicate features }\end{array}$ \\
\hline $\begin{array}{l}1.4 \text { Insert Shaft } \\
\text { into Flexure }\end{array}$ & $\begin{array}{l}\text { - Delicate parts connecting at } \\
\text { vulnerable point } \\
\text { - Very restricted view } \\
\end{array}$ & - As for 1.1 and 1.3 \\
\hline $\begin{array}{l}1.5 \text { Join Shaft to } \\
\text { Flexure }\end{array}$ & $\begin{array}{l}\text { - Very low thermal capacity } \\
\text { - Limited access to joint location }\end{array}$ & $\begin{array}{l}\text { - Angle }=90^{\circ} \pm 0.29^{\circ} \\
\text { - No distortion post-join } \\
\text { - Joint resistant to fatigue }\end{array}$ \\
\hline $\begin{array}{l}\text { 2.1 Handle/Fix } \\
\text { Sphere }\end{array}$ & $\begin{array}{l}\text { - Gravity no longer dominant } \\
\text { force acting on part } \\
\text { - Spheres unstable for gripping }\end{array}$ & $\begin{array}{l}\text { - Sphericity of part is crucial } \\
\text { - No localised damage or profile } \\
\text { changes permissible }\end{array}$ \\
\hline $\begin{array}{l}\text { 2.2 Handle/Fix } \\
\text { Shaft }\end{array}$ & $\begin{array}{l}\text { - Gravity no longer dominant } \\
\text { force acting on part } \\
\text { - WC is stiff but brittle }\end{array}$ & $\begin{array}{l}\text { - Minimise acceleration and } \\
\text { external forces } \\
\text { - Preserve the delicate features }\end{array}$ \\
\hline $\begin{array}{l}2.3 \text { Insert } \\
\text { Sphere onto } \\
\text { Shaft }\end{array}$ & $\begin{array}{l}\text { - Parts }<1 \mathrm{~mm} \text { : tension and van } \\
\text { der Waals forces will affect } \\
\text { alignment }\end{array}$ & $\begin{array}{l}\text { - Near-perfect concentricity } \\
\text { between sphere and shaft }\end{array}$ \\
\hline $\begin{array}{l}\text { 2.4 Join Sphere } \\
\text { to Shaft }\end{array}$ & $\begin{array}{l}\text { - Very limited contact area } \\
\text { - Low thermal capacity of glass } \\
\text { prevents use of thermal processes }\end{array}$ & $\begin{array}{l}\text { - No damage to parts } \\
\text { - No joint degradation } \\
\text { - No post-join deformation }\end{array}$ \\
\hline
\end{tabular}

For Assembly Task 2, it was proposed that the micro-manipulators within the Zeiss NVision should be used to deliver the probing sphere to the WC shaft for assembly. A plan was generated that would enable the existing tools to assemble the parts. Firstly, the shafts are loaded onto passive fixtures that retain them in the horizontal plane. The fixtures are then connected to the transfer shuttle for use in the FIB/SEM chamber. The sphere and SEM glue are loaded onto the same fixture for transfer into the chamber. The SEM glue is deposited into a small inverted cone machined into the surface of the fixture whilst the sphere is placed onto a small quantity of carbon. Once loaded into the chamber, the SEM beam is used for imaging to guide the operator during the assembly.

\subsection{Existing Equipment}

The Zeiss NVision is capable of performing several different tasks simultaneously upon samples held in its vacuum chamber. These include SEM, FIB, Gas Injection System (GIS), and manipulation via two Kleindiek nano resolution manipulators. The 
SEM beam offers imaging with high resolution at magnifications in excess of 300 000x. The FIB is able to machine samples at scales ranging from $10 \mathrm{~nm}$ to $10000 \mathrm{~nm}$. The functionality of the FIB is enhanced by the GIS, which can deliver several materials to be deposited onto the sample with the same resolution. The integrated manipulators have a resolution of $1 \mathrm{~nm}$ and are controllable in four degrees of freedom. They have modular tooling, enabling rapid changes of end effectors for different functions.

\section{Experimental Work}

\subsection{Assembly Task 1 Preparatory Work}

Assembly Task 1 was the task of joining the shaft to the piezoelectric flexure. This was to be done via a hole in the centre of the flexure. However, the manufacturing process used by NPL could not generate this feature reliably; as shown in Figure 5 the hole was blocked by a film formed during the manufacture of the flexure. Therefore, the initial work for this task was to machine the hole and this was attempted with the Zeiss NVision. The hole was required to be $100 \mu \mathrm{m}$ in diameter and through the approximately $15 \mu \mathrm{m}$ thick flexure. As the Zeiss NVision is designed for nano-scale machining, these are comparatively large dimensions.

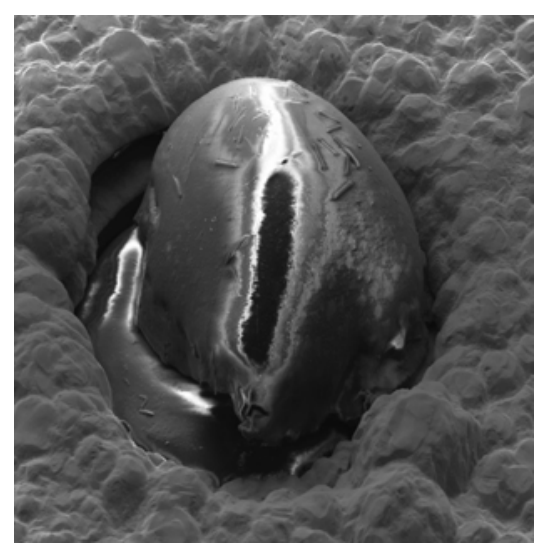

Fig. 5. Obstruction of the hole in the flexure

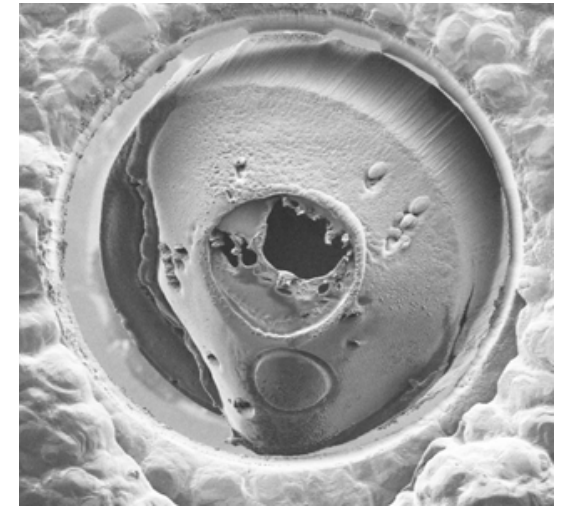

Fig. 6. The obstruction has fallen out of the flexure

The strategy adopted at first to remove the obstruction was to simply machine out the whole area. However, this was unsuccessful; after several hours of machining with high power settings ( $30 \mathrm{kV}$ and $6.5 \mathrm{nA}$ ) the FIB had only begun removing the surface of the film. The second strategy chosen was to cut a ring around the hole, allowing the obstruction to simply fall out. This was successful, though still a slow operation. Machining the ring sufficiently for the obstruction to fall out (shown in Figure 6) took approximately 5 hours of direct machining time. Including the set-up and monitoring time, several days were needed. Therefore, quicker alternatives are under investigation as this is not suitable for volume production. 


\subsection{Assembly Task 2 Trials}

Two options were considered for the manipulation of the spheres, to allow it to be joined to the shaft: use of a microgripper to hold the sphere between two jaws and use of a single needle tip. Whilst the gripper is preferable for its positive hold on the sphere, it is also likely to create indentations, at the micro and nano-scale, to the sphere. This kind of damage is not acceptable as it will affect the performance of the completed micro-CMM probe. Therefore, it was concluded to try to work with a single needle tip to move the sphere. This technique required a great deal of operator skill and patience to achieve. A view of the assembly process is shown in Figure 7. The procedure followed to facilitate assembly is as follows: (1) Locate the sphere on the fixture and bring the needle tip to it. (2) Carefully push the sphere horizontally across the fixture surface to weaken the tension forces between the carbon and the sphere bond. (3) At a critical point, the tension forces between the sphere and needle exceed that of the sphere and the carbon and the sphere then becomes attached to the needle. (4) Manoeuvre the sphere to the end of the shaft for joining.

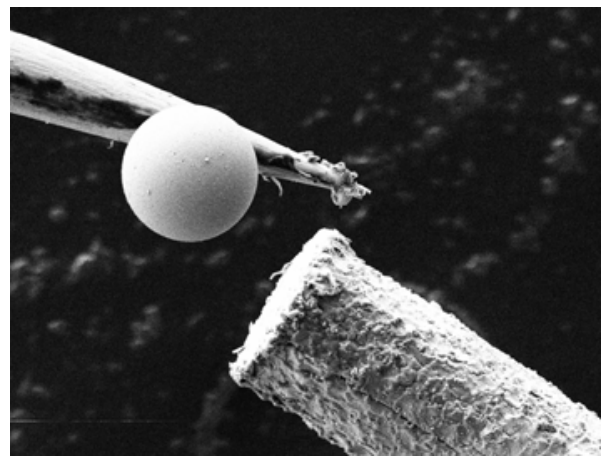

Fig. 7. SEM image showing the assembly of the sphere onto the shaft

This process does leave some residual adhesive on the surface of the sphere; however this was not visible in the FIB/SEM and should be easily removable with a nonabrasive cleaner. With the sphere in place, the next trials focused on joining the sphere to the shaft. The two main processes available were the use of a SEM-specific adhesive or the use of a FIB to deposit carbon tabs connecting the two parts. Since the adhesive would have to be manually applied to the shaft with the second manipulator, it was decided to test the feasibility of the FIB deposited tabs first. However, a number of factors adversely affect the potential success of such an approach. Firstly, FIB deposition is intended to be used at the sub-micrometre level and so producing tabs large enough to bridge the two parts in question would take in excess of twelve hours each. Secondly, as with all tab welds, it is necessary to hold both parts together and apply tabs from all sides - this is simply not possible within the vacuum chamber of the Zeiss NVision. Thus it became necessary to investigate the potential use of SEM glue. These adhesives are sufficiently viscous so as not to evaporate when placed in a vacuum chamber and are cured by a SEM beam. However, this also poses a significant challenge in giving limited time to complete the assembly as the SEM is used for 
viewing and guiding the process. As of yet the PMC has not achieved a sufficiently strong bond for the complete assembly to survive the rigours of the re-pressurisation process. However the feasibility of such an approach has been demonstrated.

\section{Conclusion}

This paper has presented the analysis and assembly planning and initial trials of an innovative micro-CMM probe. The work broke the assembly into two tasks, the assembly of the shaft to the flexure and the sphere to the shaft. Initials trials were begun for the former and multiple potential solutions were generated for the second. The results of these trials demonstrated that both solutions were feasible and worthy of more detailed examination in future research.

From the research conducted, several conclusions can be drawn:

- Utilising the Zeiss NVision for micro scale assembly of components is a feasible application, primarily due to the dexterity and accuracy of the micro manipulators.

- Microspheres can be manipulated and manoeuvred without the need for damaging grippers; however, this results in a substantial increase in the required effort, time, and operator skill to complete.

- Using FIB deposition to join two micro components is possible, but not feasible due to the time frames and the need for access to all sides of the assembly.

- Using SEM glue to join two micro components is feasible, but the process requires development and refinement.

- The FIB can be used to machine on the micro-scale, though the time frames are too great for volume production

\subsection{Further Work}

In order to facilitate the production of working prototype probes, the research efforts will focus on:

- A detailed examination of the performance of different adhesives and joining methods.

- Development of the use of the Kleindiek manipulators within the Zeiss NVision and investigation into their use outside of the chamber.

- Seeking alternatives to machining the flexure hole with the Zeiss NVision

\section{Acknowledgements}

The authors would like to acknowledge the inputs from P. Wentworth. The authors would also like to acknowledge the EPSRC 3D-Mintegration Grand Challenge Project, the National Measurement System Engineering Measurements Programme (2008-2011), the Centre of Excellence in Customised Assembly (CECA) HEFCE HEIF3 project and the East Midlands Development Agency funded Ultra Precision Machining Centre project, which provided the funding for this research. 


\section{References}

1. Tietje, C., Ratchev, S.: Design for Microassembly - A Methodology for Product Design. In: International Symposium on Assembly and Manufacturing, pp. 1-4244-0563-7/07 (2007); Proceedings of the 2007 IEEE

2. Ratchev, S., Koelemeijer, S.: Micro-assembly technologies and applications. In: Fourth International Precision Assembly Seminar. International Federation for Information Processing, Chamonix, France (2008)

3. Peggs, G.N., Lewis, A.J., Leach, R.K.: Measuring the metrology gap - 3D metrology at the mesoscopic level. Journal of Manufacturing Processes 6(1), 117-124 (2004)

4. Stoyanov, S., Bailey, C., Leach, R., Hughes, B., Wilson, A., O’Neill, W., Dorey, R., Shaw, C., Underhill, D., Almond, H.: Modelling and Prototyping the Conceptual Design of 3D CMM Micro-probe. In: Proceedings of the IEEE 2nd Electronics System Integration Technology Conference, pp. 193-198 (2008)

5. Haitjema, H., Pril, W.o., Schellekens, P.H.J.: Development of a silicon-based nanoprobe system for three-dimensional measurements. CIRP Annals - Manufacturing Tech. 50, 365 368 (2001)

6. Van Brussel, H.P.: Assembly of Microsystems. CIRP Opening Session. Annals of the ClRP 49/2/2000 (2000)

7. Rampersad, H.: Integrated and Simultaneous Design for Robotic Assembly. John Wiley \& Sons Ltd., Chichester (1994)

8. Smale, D., Ratchev, S., Segal, J., Leach, R.K., Claverly, J.D.: Assembly of the stem and tip of an innovative micro-CMM probe. In: Euspen 9th International Lamdamap (Laser Metrology and Machine Performance) Conference, Brunel, London, UK (2009) 